\title{
Effect of Ocimum basilicum on mesenchymal stem cell proliferation and differentiation: Does the effect change according to niches?
}

\author{
Ayşegül H. MENDİ*1 ${ }^{*}$ Beyza GÖKÇINAR YAĞCI², Nurdan SARAÇ³, \\ Mustafa KIZILOĞLU ${ }^{4}$, Aysel UĞUR ${ }^{1}$, Derviş YILMAZ ${ }^{4}$, Duygu UÇKAN ${ }^{2}$
}

${ }^{1}$ Gazi University Faculty of Dentistry Department of Medical Microbiology, Ankara, Turkey

${ }^{2}$ Hacettepe University, PEDI-STEM Center for Stem Cell Research and Development, Ankara, Turkey

${ }^{3}$ Mugla Sitki Kocman University, Faculty of Sciences, Department of Biology, Mugla, Turkey

${ }^{4}$ Gazi University, Faculty of Dentistry Department of Oral and Maxilofacial Surgery, Ankara, Turkey

Received: 28 April 2017 - Revised: 07 June 2017 - Accepted: 23 June 2017

\begin{abstract}
It is a big issue that reduced bone density and large fractıres in dentistry and orthopedics. Side effects caused by synthetic drugs lead to medical and ethical problems. Thus, plants and medicinal plant research take attention. Aim of this preliminary in vitro study is to investigate the effect of Ocimum basilicum extract on dental pulp (DP) and bone marrow (BM) derived mesenchymal stem cell (MSC) proliferation, osteogenic differentiation and immunological response to TNF- $\alpha$. Human dental pulp tissue was obtained from patients (15-20 years of age) who were undergoing extraction of third molars for orthodontic reasons at the Department of Oral and Maxillofacial Surgery, University of Gazi University*. xCELLigence system was used to determine prolfieration of DP- and BM-MSCs. Adipogenic and osteogenic differentiation was shown and calcium concentration, osteocalcin and osteonectin levels were examined. Inflammatory environment was mimiced through TNF- $\alpha$ stimulation and IL-6 and IL-10 levels were defined by ELISA. Doubling time mwith O. basilicum was found in DP- MSCs (38 h) and BM-MSCs (76 h). IC50 value was shown as $148 \mu \mathrm{g} / \mathrm{mL}$ in DP-MSCs and $178 \mu \mathrm{g} / \mathrm{mL}$ in BM-MSCs. Calcium concentration of BM-MSCs was found decreased in O. basilicum treated groups. Level of ostoenectin was reduced in $\mathrm{O}$. basilicum treated cells suggesting that the Extract accelerated the osteogenic differentiation. We suggest that $\mathrm{O}$. basilicum could be a smart ostoeinductive agent where BM-MSCs should be investigated further. Rich flora of Turkey is an opportunity for us and encourangement can easily give inside to medicinal plant investigations. *B.30.2.GÜN.0.20-122 Ethics Committee Report
\end{abstract}

Keywords: mesenchymal stem cell, osteogenic differentiation, dentistry, plant extract, Ocimum basiliicum

\section{INTRODUCTION}

Dental pulp mesenchymal stem cells (DP-MSCs) are a type of mesenchymal stem cell (MSCs) found in the cell-rich zone of the pulp tissue of teeth [1]. DP-MSCs have a strong selfrenewal ability and the potential for multi-directional differentiation, which gives them great therapeutic potential for repairing damaged and/or defective tissue [2].

The presence and maintenance of alveolar bone is tooth dependent. After tooth extraction, the alveolar bone is slowly resorbed down to the body of the jaw bones. In cases of complete tooth loss, there is progressive bone resorption, which can result in extensive atrophy of the jaw

\footnotetext{
*Corresponding Author E-mail: aysegulmendi@gmail.com
} 
bones and lead to major clinical challenges for implant placement and the construction of dental prostheses [3]. Even without therapeutic intervention, the periodontium can exhibit a significant capacity for regeneration. However, such endogenous activity has limited capacity for periodontal regeneration. In addition, the impairment of bone formation increases in patients with osteoporosis and diabetes mellitus and related conditions. We hpothesize that a natural agent that maintains MSCs viability, promotes osteogenic differentiation while modulating the immunological response could achieve success in regeneration during healing and may also prevent bone resorption and improve regeneration.

Ocimum basilicum belonging to the Lamiaceae family, is a pleasent by smelling perennial shrub which grows in several regions all over the World [4, 5]. O. basilicum is one of the species used for the commercial seasoning. O. basilicum is a condimental plant cultivared in some parts of Turkey, and used frequently in soups, desserts, pickles, pizza, spagetti sauce, egg, cheese dishes, tımato juice, dressings, meat products etc. Also used in pharmacy for diuretic [5]; and its oil has been found to be beneficial for the alleviation of mental fatigue, colds, spasms, rhinitis, and as a first aid treatment for wasp stings and snake bites. The essential oil has antifungal, physicochemical and inset repelling activiity [6-9]. It is also regarded as highly antiseptic and has been applied in boths to prevent postpartum infections.

Ocimum group of species have been shown to possess a wide range of chemopreventive and medicinal activities [10-13]. In addition, extracts of the leaves displayed powerful antioxidant activity in various assay models $[14,15]$. O. basilicum had been found to contain linalool, eugenol, methyl chavicol, methyl cinnamate, ferulate, methyl eugenol, triterpenoids and steroidal glycoside known to exhibit antioxidant activities [16-18]. It is therefore possible that the extracts may serve as a remedy by blocking or intercepting the activity of environmentally acquired toxins such as mycotoxins, insecticides and pesticides.

Although various physiological activities of $\mathrm{O}$. basilicum have been demonstrated, its link to osteogenic differentiation of mesenchymal stem cells has never been explored. In the present study, we hypothesized that O. basilicum could maintain the viability of DP-MSCs, induce promote their osteogenic differentiation, which may enable the successful regeneration of hard tissues. We also used bone marrow (BM) derived MSCs as control.

\section{MATERIAL and METHODS}

\subsection{Extraction of Plant Samples}

O. basilicum flower buds were purchased from the local market in Mugla, Turkey. The air-dried plant samples were extracted with ethanol (Merck, Taufkirchen Germany) using a Soxhlet apparatus. The extracts were evaporated and stored in sterile opaque glass bottles under refrigerated conditions until use. The dried extract was prepared in DMEM-LG with 10\% foetal bovine serum (FBS) (Invitrogen, Carlsbad, Calif., USA), 1\% L-glutamine (Sigma, Taufkirchen Germany) and 1\% Penicillin-Streptomycin (Invitrogen, Carlsbad, Calif., USA) for the studies.

\subsection{Isolation and Culture of Dental Pulp Mesenchymal Stem Cells}

Human dental pulp tissue was obtained from patients (15-20 years of age) who were undergoing extraction of their third molars for orthodontic reasons at the Department of Oral and Maxillofacial Surgery, University of Gazi, Ankara. All patients provided informed consent (Ethics Commit. Rep. No: G.Ü. B30.2. GÜN 0.21.71.00). After the tooth surfaces were disinfected, the teeth were mechanically fractured, and the dental pulp was gently isolated with forceps. The pulp tissue was rinsed in $\alpha$-MEM supplemented with $2 \mathrm{nM} \mathrm{L}$-glutamine, $100 \mathrm{U} / \mathrm{mL}$ penicillin, $100 \mu \mathrm{g} / \mathrm{mL}$ streptomycin and 10\% fetal bovine serum (FBS, Invitrogen) (hereafter referred to as the MSC culture medium), after which it was minced into fragments of 1 to 2 mm3. The tissue fragments were cultured in T75 Nunc plates in the MSC culture medium at 
$37^{\circ} \mathrm{C}$ in a humidified atmosphere containing 5\% CO2. Human BM-MSCs were a kind gift from Hacettepe University Center for Pediatric Stem Cell and Research and Development. BMMSCs were suspended at a concentration of $1 \times 106$ cells $/ \mathrm{mL}$ in MSC culture medium. The culture media was changed every 2 to 3 days, and the cell cultures were monitored regularly with an inverted microscope (Olympos CKX41, Tokyo, Japan). Upon reaching 70-80\% confluence, the cells were harvested with $0.05 \%$ Trypsin/EDTA (Sigma, Taufkirchen Germany) and sub-cultured for further experiments.

\subsection{Immunophenotypic Analysis}

The culture-expanded adherent cells were analysed by flow cytometry (BD FACSAria, USA). The antibody panel included CD29- FITC (e-bioscience, USA); CD73-PE (BD, USA), CD 90-PE (BD, USA), CD44-PE (e-bioscience, USA) as mesenchymal stromal markers, as well as their isotype controls. CD45-FITC (BD, USA); CD14-PE (BD, USA); and CD34-FITC (BD USA) were used as haematopoietic markers to exclude cells of haematopoietic origin. The relative frequencies of the cells that expressed the respective surface markers were analysed using FACS Diva software 6.0.0 (BD) by acquiring 10,000 events for each sample.

\subsection{Effect of O. basilicum on Proliferation of the MSCs Using the xCELLigence System}

Initially we examined the proliferation of DP-MSCs in a 24 well culture microplate seeded at a density of 5000 cell/cm2. DP-MSCs were cultured with different concentrations (1, $3,5,10,25,50,75$, and $100 \mu \mathrm{g} / \mathrm{mL}$ ) of $\mathrm{O}$. basilicum up to the control group had $90 \%$ confluency. Cells were counted by trypan blue method and the three concentrations which induced the cell number was selected for xCELLigence analysis. The xCELLigence system was used according to the manufacturer's instructions [19]. Briefly, the E-plate 96 was connected to the xCELLigence system and verified in the cell culture incubator to ensure that proper electrical contacts were established, and the background impedance was measured. Subsequently $100 \mu \mathrm{l}$ of MSCs culture media containing 5, 10 and $25 \mu \mathrm{g} / \mathrm{mL}$ O. basilicum extract and standart culture media as control were added into each well of E-plate 96. Meanwhile, the cells were resuspended $(5000 \mathrm{cells} / \mathrm{cm} 2)$ in MSC culture media for their concentration. $100 \mu \mathrm{l}$ of each cell suspension was added to each well, in order to determine effect of $\mathrm{O}$. basilicum extract on cell proliferation. Cell growth and proliferation were monitored every $30 \mathrm{~min}$ for up to $290 \mathrm{~h}$. The growth curve, cell index, and doubling time (DT) values were determined.

\subsection{Effect of O. basilicum on MSCs Differentiation}

The concentration that decreased the doubling time and increased the proliferation was selected based on the results from the xCELLigence system analysis. The selected concentration was added to the osteogenic and adipogenic differentiation media [20]. The images were obtained with a CKX41 digital imaging microscope (Olympus, Tokyo, Japan). The secreted Osteocalcin $(\mathrm{OCN})$ and Osteonectin $(\mathrm{ON})$ levels in the supernatants were assessed using an ELISA kit according to the manufacturer's instructions (R\&D Systems, Inc. Minneapolis). The limits of detection for the ELISA were 1.2 to $75 \mathrm{ng} / \mathrm{mL}$ for OCN and 1.56 to $50 \mathrm{ng} / \mathrm{mL}$ for $\mathrm{ON}$.

\subsection{Determining the Immunomodulatory Activities}

DP- and BM-MSCs were plated at a density of 5000 cell $/ \mathrm{cm} 2$ in 96 -well culture plates and allowed to attach overnight. The cells were pretreated with $10 \mu \mathrm{g} / \mathrm{mL} \mathrm{O}$. basilicum extract for $1 \mathrm{~h}$, and $10 \mathrm{ng} / \mathrm{mL}$ TNF- $\alpha$ were then added. After $24 \mathrm{~h}$, the cell culture supernatants were collected and stored at $-80^{\circ} \mathrm{C}$ for use in the IL-6, IL-10 ELISAs, according to the manufacturer's instructions. The ELISA limits were $0,052-0,118 \mathrm{pg} / \mathrm{mL}$ for IL-6 and $0,39-25 \mathrm{pg} / \mathrm{mL}$ for IL- 10 . Media alone, with TNF- $\alpha$, and with T. spicata var. intricata were included as controls. 


\subsection{Statiscal Analysis}

All calculations were performed using the RTCA integrated software of the xCELLigence system. The RTCA software fits the curve of the selected sigmoidal dose response equations to the experimental data points. The data are presented as the mean $(\mu \mathrm{g} / \mathrm{mL}) \pm \mathrm{SD}(\mathrm{n}=4)$. For the proliferation experiments, the statistical analysis was performed using one-way analysis of variance (ANOVA) $(\mathrm{p}<0.05)$.

\section{RESULTS and DISCUSSIONS}

\subsection{Identification of MSCs}

The common MSC markers (CD29, CD73, CD44, and CD90) were constitutively positive $(>95 \%)$ and the hematopoietic markers (CD14, CD34, and CD45) were negative (>95) in all samples tested, indicating a mesenchymal origin of the cells (Figure 1).
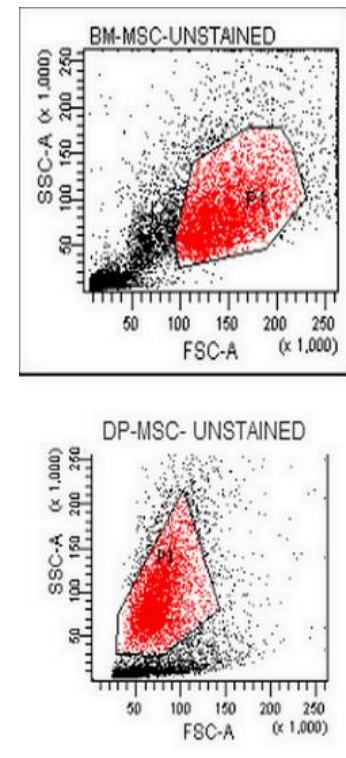

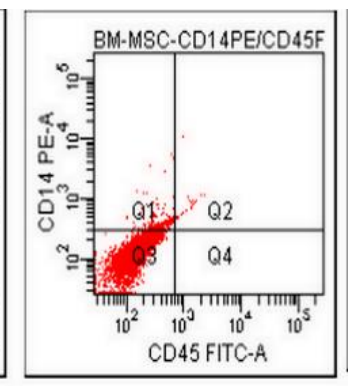

DP-MSC- CD45/CD14

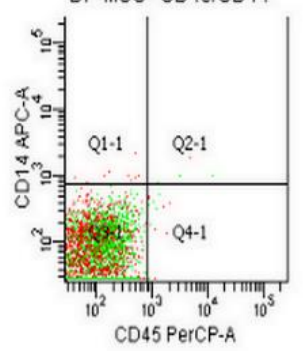

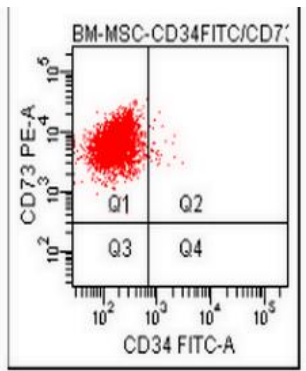
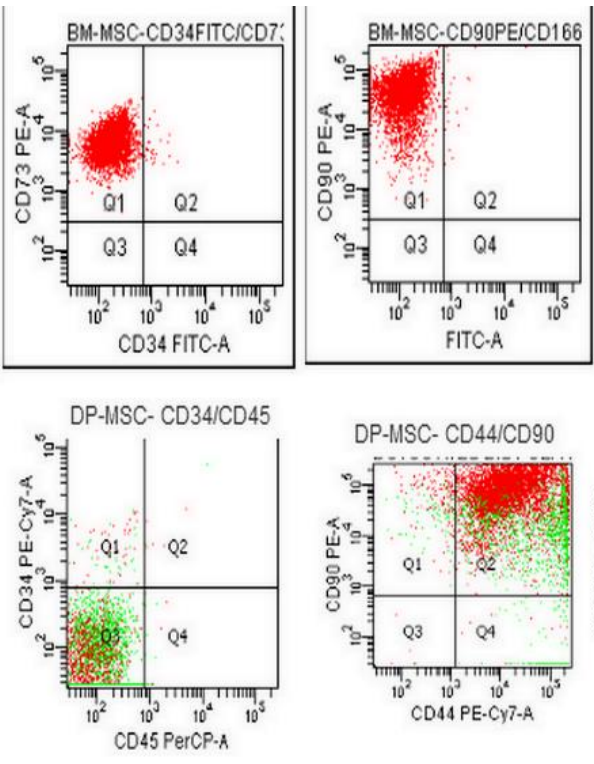
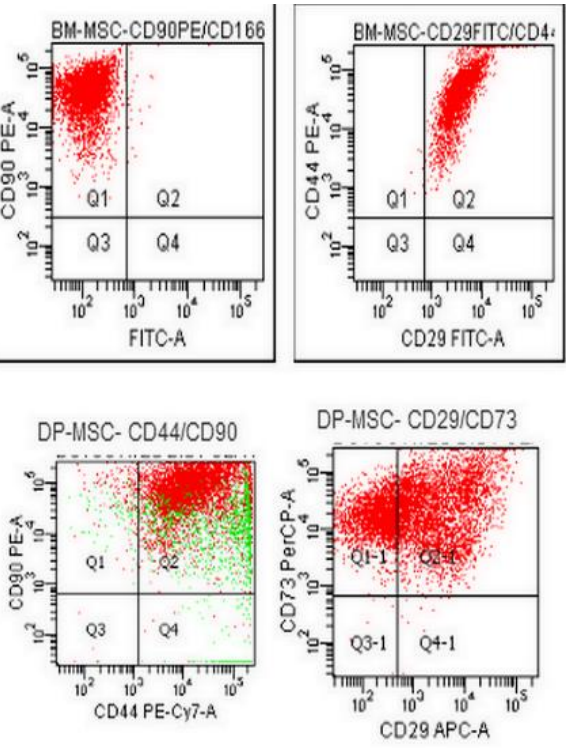

Figure 1. Surface markers of DP-MSCs and BM-MSCs

\section{2. xCELLigence Assays}

Trypan blue assay exhibited an interesting result that cell number at $1 \mu \mathrm{g} / \mathrm{mL}$ was higher than the Control (Figure 2). However at $3 \mu \mathrm{g} / \mathrm{mL}$ the cell number decreased at a ration of $21 \%$, and at the subsequent concentration $5 \mu \mathrm{g} / \mathrm{mL}$ cell number was found increased to the $50 \mu \mathrm{g} / \mathrm{mL}$ concentration. At 75 and $\mu \mathrm{g} / \mathrm{mL}$ the cell number was found reduced afor a $42 \%$ ratio. We estimated at $100 \mu \mathrm{g} / \mathrm{mL}$ the cell number would decrease, however it increased again . 


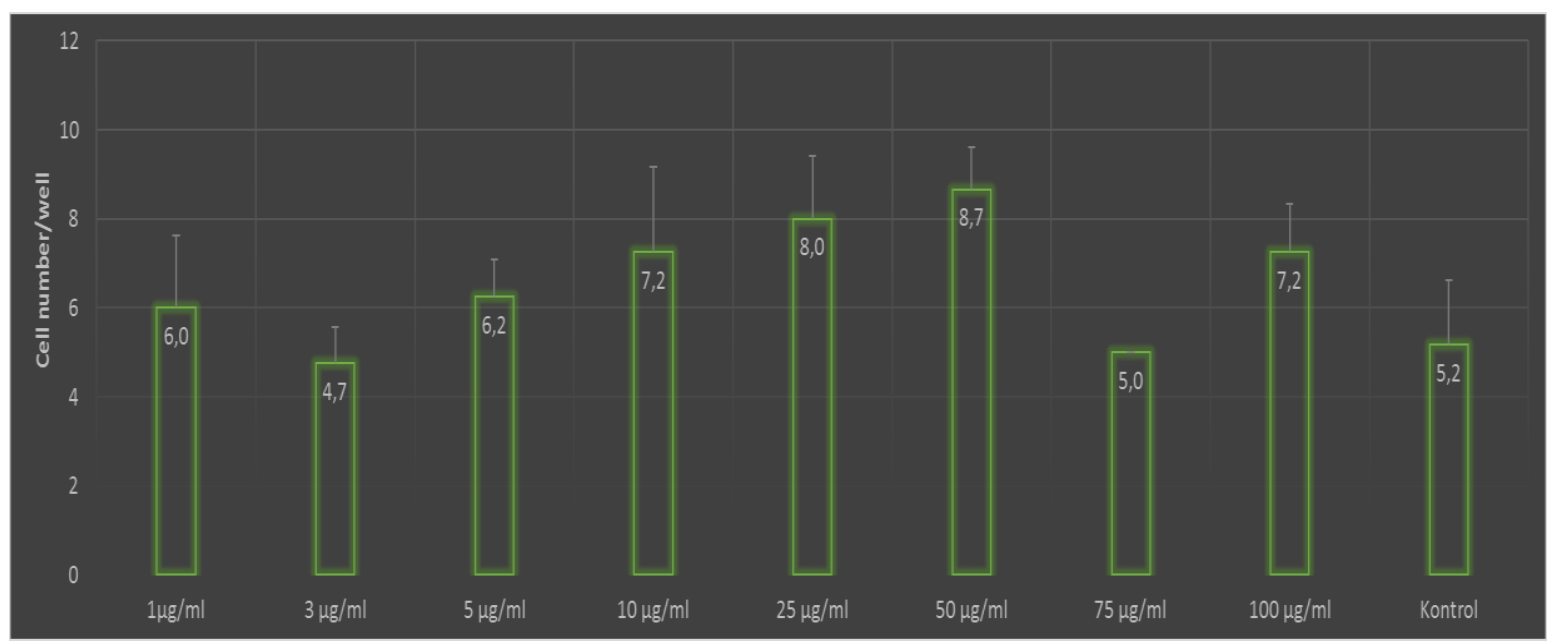

Figure 2. Trypan Blue Assay results.

Subsequently we conducted the xCELLigence assay for the same concentrations and found different values. of course, we could examine more parameters than the Trypan Blue Assay. We obtained the growth curves of DP-MSCs and BM-MSCs. Using the xCELLigence system, we obtained a growth curve for MSCs which provides information on three parameters: the lag phase before cell proliferation is initiated after subculture, the DT in the middle of the exponential growth phase, and the terminal density [2]. The lag phase is the time period that the cells are recovering from trypsinization, synthesizing new extracellular matrix and cytoskeleton, and adapting for attachment, spreading and re-entering the cell cycle. Cells do not divide in the lag phase [21]. We could conclude that $O$. basilicum showed similar adhesive effect on DP-MSCs till 98h whilst BM-MSCs were adhered and proliferated more than the Control group (Figure 3). $200 \mu \mathrm{g} / \mathrm{mL}$ showed lethal effect in BM-MSCs while $1 \mu \mathrm{g} / \mathrm{mL}$ but not $200 \mu \mathrm{g} / \mathrm{mL}$ for DP-MSCs. Ideally, towards the end of the log phase, the culture becomes confluent and its growth rate reduces, and in some cases, cell proliferation ceases. At this stage, the culture enters the plateau, or stationary phase, in which cell division is balanced by cell loss. DP-MSCs were still alive where BM-MSCs began to reduced their cell number. We determined the cell indexes for the time intervals of the lag, log, and plateau phases using the growth curve. xCelligence assay showed that cells treated with $O$. basilicium had lower adhesion, but similar viability when compared with control cells. The doubling time (DT) was reduced at $10 \mu \mathrm{g} / \mathrm{mL}$ in DP-and BM-MSCs. Thus, O. basilicum could be a good proliferation inducer. The IC50 value was found 7,7 $\mu \mathrm{g} / \mathrm{mL}$ for DP-MSCs and $17 \mu \mathrm{g} / \mathrm{mL}$ for BM-MSCs at $290 \mathrm{~h}$. Oriental medicine practices are primarily based on personal experience, which often result in unknown mechanisms and difficulties in dose specification. We used a real-time monitored system, $x C E L L i g e n c e$, to determine the effective concentration. The xCELLigence system is much more sophisticated than other conventional endpoint, cell-based assays. Real-time and continuous monitoring enable the label-free assessment of cell proliferation, viability, and cytotoxicity by showing the physiologic state of the cells and eliminating expensive reagents that are used in conventional cell analyses [21]. 

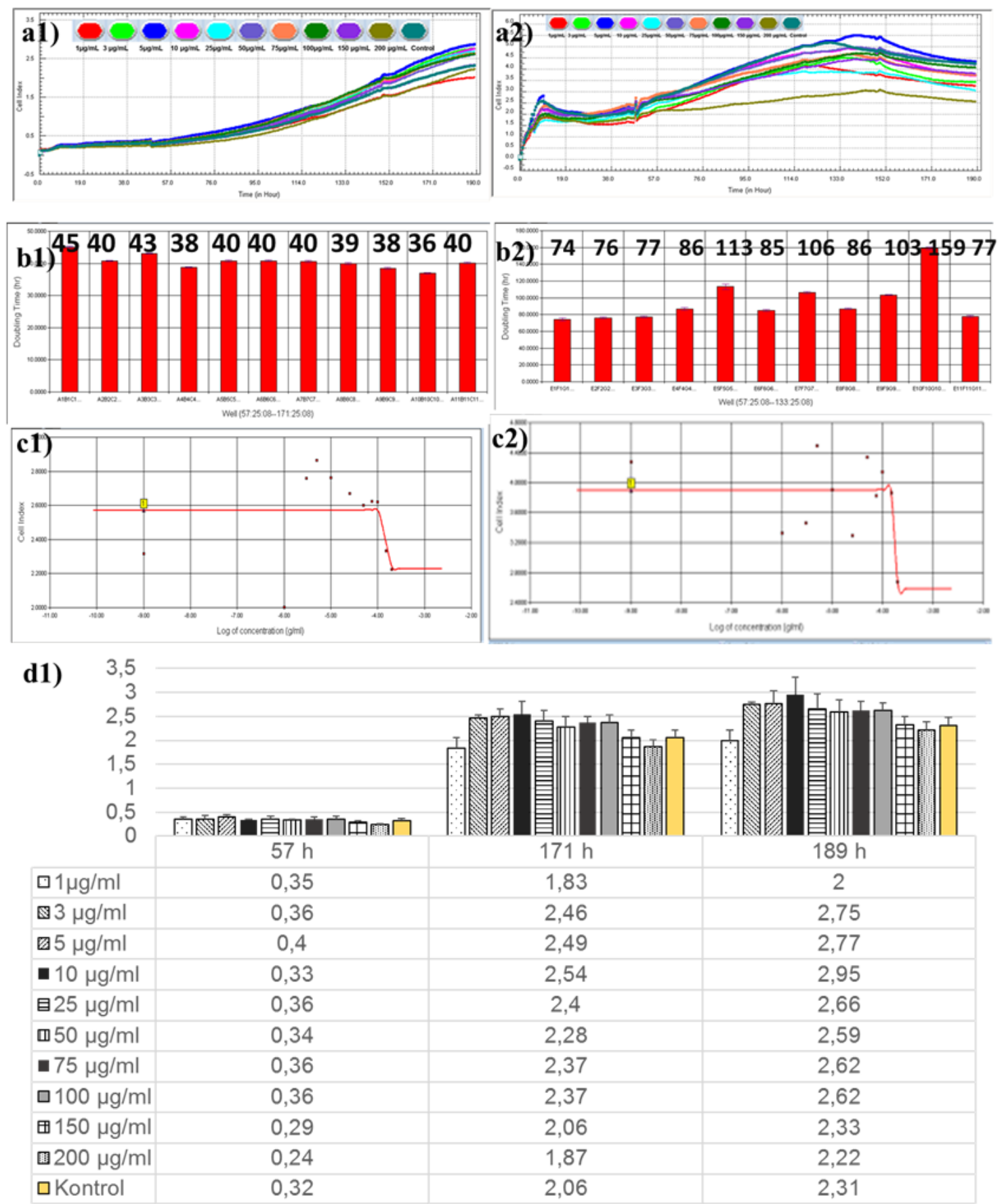

Figure 3. xCELLigence analysis of DP-MSCs and BM-MSCs. Growth curve of the cells. a1) DPMSCs, a2) BM-MSCs; doubling time of the DP-MSCs (b1) and BM-MSCs (b2); IC50 values for DPMSCs (c1) and BM-MSCs (c2); the cell indexes at lag mid log, and stationary phases (d1) of the cells were determined.

\subsection{Differentiation Assays of MSCs}

The differentiation characteristics features of the cells were studied. (Figure 4). Adipogenic differentiation exhibited a quite difference in DP-MSCs treated with $O$. basilicium. Approximately $20 \%$ of the cells became rounder; however, no lipid droplets were observed in DP-MSCs. In contrast to adipogenic differentiation, the DP-MSCs underwent rapid osteogenic differentiation. Calcium granules similar to bone nodules were seen in BM-MSCs. The osteogenic differentiation potentials of DP-MSCs in vitro and in vivo have been well documented in a variety of studies $[2,22]$. Our findings were agree with those of Gronthos et 
al (2000) who expanded DP-MSCs from single-cell clones and demonstrated that they exhibited osteogenic differentiation but did not form lipid-laden adipocytes [2]. We found well deposited calcium granules in $O$. basilicum treated Group in DP-MSCs. Surprisingly in BM-MSCs osteogenic differentiation did not found on O. basilicum Group. To determine the osteogenic markers in culture supernatant we examined osteonectin and osteocalcin levels by ELISA. During osteogenic cell differentiation, the markers of the undifferentiated cells are gradually turned off, and the differentiation markers are sequentially expressed. We observed the sequential secretion of proteins at the end of the assay, in which the ON levels decreased in the $O$. basilicum-treated group compared to the control group. ON is an early marker of osteogenesis that is synthesized by preosteoblasts and has less affinity to collagen. The ON transcript is quite stable, with a half-life of $>24$ hours under conditions of transcription arrest [23].

DENTAL PULP MSCs BONE MARROW MSCs

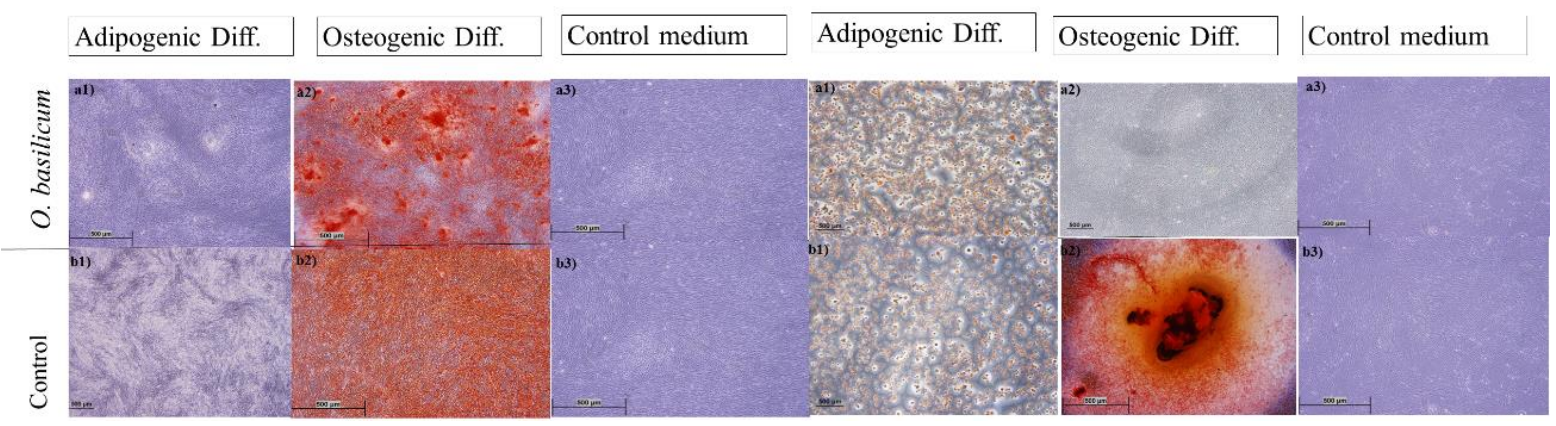

Figure 4. Differentiation potential of DP-MSCS and BM-MSCS. adipogenic differentiation was not shown in DP-MSCs while BM-MSCs were well differentiated.

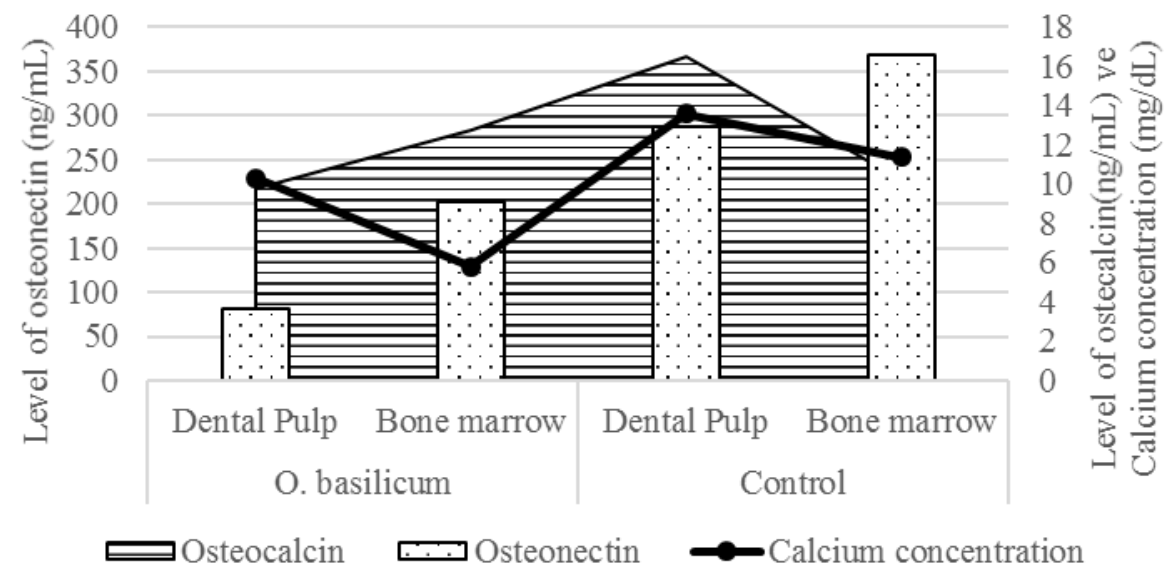

Figure 5. Osteonectin, osteocalcin and calcium concnetration of DP-MSCs and BM-MSCs with $O$. basilicum

So we suggested that $O$. basilicum may accelarate the ostegenic differentiation in both DP- and BM-MSCs since the ON level was reduced signed to loose the stability being secreted early. O. basilicum-treated BM-MSCs exhibited higher OCN levels than the untreated BMMSCs while DP-MSCs did not. OCN is the represent of calcium granules, however we could not see the calcium graules in BM-MSCs and the calcium concetrations were too low either.

Therefore, $O$. basilicum could be a safe inducer for both healthy and medically compromised patients. In a study of essential oils of different geographical origins, Lawrence (1988) found that the main constitutents of the essential oil of basil are methylchavicol, eugenol, 
methyleugenol and methyl cinnamate [24]. Eugenol and methyl eugenol remarked our previous study that eugenol containing S. aromaticum inhibited the osteogenic differentiation [25]. Similarly Anpo et al. (2011) provided evidence that eugenol/S. aromaticum reduces collagen synthesis, which play a critical role in osteogenesis [26]. From this point we suggest that $O$. basilicum may inhibit the collagen synthesis that leads to inhibit calcium granulation in BMMSCs.

\subsection{Determining the Preventive Effect of $O$. basilicum on the Inflammatory Response of MSCs Following TNF- $\alpha$ Stimulation}

Figure 6 shows the anti-inflammatory activities of $O$. basilicum. Obtained data showed an antinnflammatory and immunomodulatory effect of the extract. Both IL- 6 and IL-10 were present in the DP- and BM-MSCs cell culture supernatants [27]. Our results showed that when the extract used alone the IL-6 level was increased in BM-MSCs while it was decreased in DPMSCs. On the other hand in contrast with alone used, the BM-MSCs were pretreated with $O$. basilicum, before TNF- $\alpha$ stimulation the IL-6 level were found decreased. We asked the literature if any relation was observed between increased IL-6 and inhibition of ostoegenic differentiation in BM-MSCs. It was clear that osteoblasts express low levels of IL-6 R [28]. Numerous reports indicate that IL-6 + IL-6R enhance in vitro differentiation on osteoblasts or osteoblast precursor [29]. On the other hand, there are reports showing the inhibitory effect of IL-6 type cytokines on bone formation [30-33]. It is possible that on precursor cells, IL-6 type cytokines would stimulate the first stages of differentiation but when stage progresses to maturation they would prevent stimulation by reduced ostoeblastic marker expression and enhanced apoptosis. So the study should be forther analysed for whole ostegenic markers and IL-6 secretion.

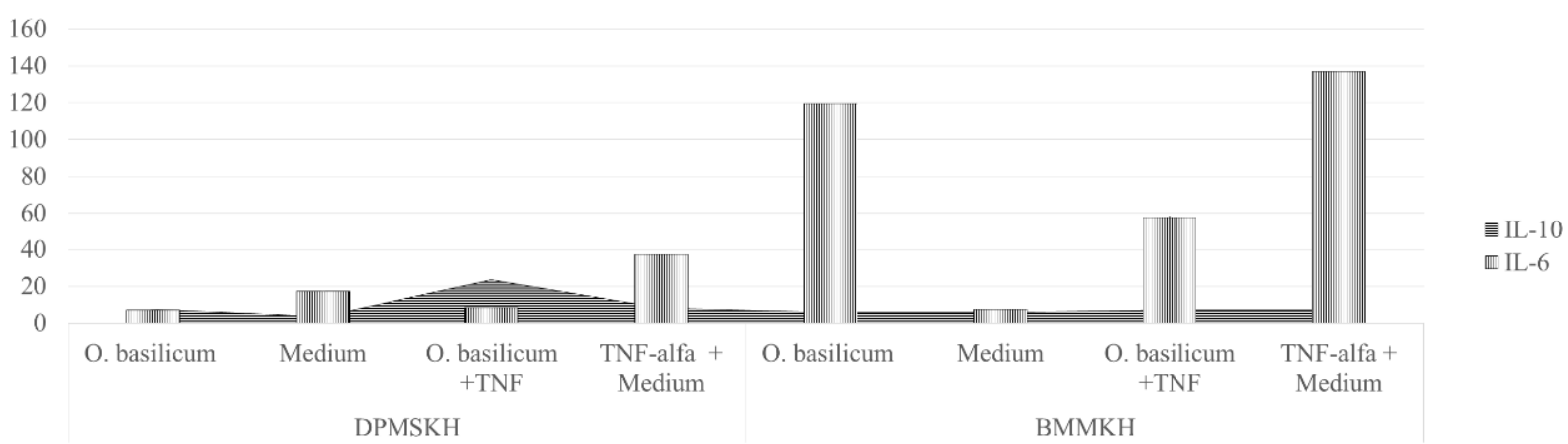

Figure 6. IL-6 (a) and IL-10 (b) level determined in the culture supernatant of DP and BM-MSCs.

Here we demonstrated that $O$. basilicum effect differently on BM- and DP- mesenchymal stem cells. It is important to determine the differentiation, and proliferation of cells with promising inductive agents. Studies should avoid to suggest any plant extract as an agent without evidence of safe.

\section{Acknowledgement}

This study was supported by the Turkish Scientific and Technological Research Council (TUBITAK), Project no: SBAG 113S448. We specially thank to Prof. Dr. Petek Korkusuz and Sevil Köse for assistance in xCELLigence assays and analysis.

\section{Conflict of Interests}

Authors declare that there is no conflict of interests. 


\section{REFERENCES}

[1] Estrela, C., Alencar, A.H.G.D., Kitten, G.T., Vencio, E.F., Gava, E. (2011). Mesenchymal stem cells in the dent al tissues: perspectives for tissue regeneration, Brazilian Dental Journal, 22, 91-98.

[2] Gronthos, S., Mankani, M., Brahım, J., Robey, P.G., Shi S. (2000). Postnatal human dental pulp stem cells (DPSCs) in vitro and in vivo, Proceedings of the National Academic Sciences, 97, 13625-13630.

[3] Hoiruchi, K., Amizuka, N., Takeshita, S., Takamatsu, H., Katsuura, M., Ozawa, H., Toyama, Y., Bonewald, L.F., Kudo, A. (1999). Identification and chracterization of a novel protein, perostin, with restricted expression to periosteum and periodontal ligament and increased expression by transforming growth factor beta. Journal of Bone and Mineral Research, 14, 1239-1249.

[4] Akgül A. (1989). Volatile oil composition of sweet basil (Ocimum basilicum L.) cultivating in Turkey. Nahrung, 33, 87-88.

[5] Baritaux, O., Richard, H., Touche, J., Derbesy, M. (1992): Effects of drying and storage of herbs and spices on the essential oil. Part I. Basil, Ocimum basilicum L., Flavour and Fragrance Journal, 7, 267-271.

[6] Lahariya, A.K., \& Rao, J.T. (1979). In vitro antimicrobial studies of the essential oil of Cyperus scariosus and Ocimum basilicum, Indian Drugs, 16, 150-152

[7] Dube, S., Upadhyay, P.D., Tripathi, S.C. (1989). Antifungal, physicochemical and insectrepelling activity of the essential oil of Ocimum basilicum, Canadian Journal of Botany, 67, 2085-2087.

[8] Özcan M. (1998). Inhibitory effects of spice extracts on the growth of Aspergillus parasiticus NRRL 2999 strain, Z. Leb.- Mitt. Unters. u- Forsch. A, 207, 253-255.

[9] Martins, A.P., Salgueiro, L.R., Vila, R., Tomi, F., Canigueral, S., Casanova, J., Proença Da Cunha, A., Adzet, T. (1999). Composition of the essential oils of Ocimum canum, O. gratissimum and O. minimum, Planta Medica, 65, 187-189.

[10] Godhwani, S., Godhwani, J.L., Vyas, D.S. (1987). Ocimum sanctum: An experimental study evaluating its anti-inflammatory, analgesic and antipyretic activity in animals, Journal of Ethnopharmacology, 21, 153-163.

[11] Banerjee S., Prashar R., Kumar A., Rao, A.R. (1996). Modulatory influence of alcoholic extract of ocimum leaves on carcinogen-metabolizing enzyme activities and reduced glutathione levels in mouse. Nutrition and Cancer, 25, 205-217.

[12] Karthikeyan, K., Ravichandran, P., Govindasamy, S. (1999). Chemopreventive effect of Ocimum sanctum on dmba-induced hamster buccal pouch carcinogenesis, Oral Oncology, 35, 12-19

[13] Rastogi, S., Shukla, Y., Paul, B.N., Chowdhuri, D.K., Khanna, S.K., Das, M. (2007). Protective effect of Ocimum sanctum on 3-methylcholanthrene, 7, 12-dimethylbenz(a)anthracene and aflatoxin b1 induced skin tumorigenesis in mice, Toxicology and Applied Pharmacology, 224, 228-240.

[14] Gulcin, I., Elmastas, M., Aboul-Enein, H.Y. (2007). Determination of antioxidant and radical scavenging activity of basil (ocimum basilicum l. Family lamiaceae) assayed by different methodologies, Phytotherapy Research, 21, 354-361.

[15] Jayasinghe, C., Gotoh, N., Aoki, T., Wada, S. (2003). Phenolics composition and antioxidant activity of sweet basil (Ocimum basilicum L.), Joural of Agriculture and Food Chemistry, 51, 4442-4449.

[16] Siddiqui, B.S., Aslam, H., Ali, S.T., Begum, S., Khatoon, N. (2007a). Two new triterpenoids and a steroidal glycoside from the aerial parts of Ocimum basilicum, Chemical and Pharmaceutical Bullettin (Tokyo), 55, 516-519. 
[17] Siddiqui, B.S., Aslam, H., Begum, S., Ali, S.T. (2007b). New cinnamic acid esters from Ocimum basilicum, Natural Product Research, 21, 736-741.

[18] Zheljazkov, V.D., Callahan, A., Cantrell, C.L. (2008). Yield and oil composition of 38 basil (Ocimum basilicum L.) accessions grown in mississippi, Journal of Agriculture and Food Chemistry, 56, 241-245.

[19] Roche Diagnostics. (2008). GmbH. Introduction of the RTCA SP Instrument. RTCA SP Instrument Operator's Manual, A. Acea Biosciences, Inc ; 14-16.

[20] Pittenger, M.F., Mackay A.M., Beck S. (1999). Multilineage potential of adult human mesenchymal stem cells. Science, 284, 1168-1170.

[21] Hensten-Pettersen, A. (1988). Comparison of the methods available for assessing cytotoxicity. International Endodontic Journal, 21, 89-99.

[22] D'aquino, R., Graziano, A., Sampaolesi, M., Laino, G., Pirozzi, G., De Rosa, A., Papaccio, G. (2007). Human postnatal dental pulp cells co-differentiate into osteoblasts and endotheliocytes: a pivotal synergy leading to adult bone tissue formation, Cell Death and Differentiation, 14, 1162-1171.

[23] Dole, N.S., Kapinas, K., Kessler, C.B., Yee, S., Adams, J.D., Pereira, R.C., Delany, A.M. (2015). A single nucleotide polymorphism in osteonectin 3' untranslated region regulates bone volume and is targeted by miR-433, Journal of Bone and Mineral Research, 2015; 30, 723-32.

[24] Lawrence, B.M. (1985). A review of the world production of essential oil, Perfume and Flavorance, 10, 2-16.

[25] Mendi, A., Gökçınar Yağcı, B., Sarac, N., Kızıloğlu, M., Ugur, A., Yılmaz, D., Uçkan, D. (2017). The effects of Syzygium aromaticum, Cinnamomum zeylanicum and Salvia triloba extracts on proliferation and differentiation of dental pulp stem cells, Journal of Applied Oral Sciences, accepted.

[26] Anpo, M., Shirayama, K., Tsutsui, T. (2011) Cytotoxic effect of eugenol on the expression of molecular markers related to the osteogenic diffferentiation of human denetal pulp cells, Odontology, 99, 188-192

[27] Ishihara, K., Hirano, T. (2002). IL-6 in autoimmune disease and chronic inflammatory proliferative disease. Cytokine and Growth Factor Reviews, 13, 357-68.

[28] Lieder, R., Sigurjonsson, O.E. (2014). The effect of recombinant human interleukin-6 on osteogenic differentiation and YKL-40 expression in human, bone marrow derived mesenchymal stem cells, Bioresearch Open Access, 3, 29-34.

[29] Franchimont, N., Wertz, S., Malaise, M. (2005). Interleukin-6: an osteotropic factor influencing bone formation?, Bone, 37, 601-606.

[30] Chipoy, C., Berreur, M., Couillaud, S., Pradal, G., Vallette, F., Colombeix, C. (2004). Downregulation of osteoblast markers and induction of the glial fibrillary acidic protein by oncostatin M in osteosarcoma cells require PKCdelta and STAT3, Journal of Bone and Mineral Research, 19, 1850-1861.

[31] Malaval, L., Aubin, J.E. (2001). Biphasic effects of leukemia inhibitory factor on osteoblastic differentiation, Journal of Cell Biochemistry, 81, 63-70.

[32] Malaval, L., Liu F., Vernallis A.B., Aubin J.E. (2005). GP130/OSMR is the only LIF/IL-6 family receptor complex to promote osteoblast differentiation of calvaria progenitors. Journal of Cell Physiology, 204, 585-593.

[33] Falconi, D., Aubin, J.E. (2007). LIF inhibits osteoblast differentiation at least in part by regulation of HAS2 and its product hyaluronan. Journal of Bone and Mineral Research, 22, 1289-1300. 